\title{
RESTITUIÇÃO DO ICMS PAGO A MAIOR NOS CASOS DE SUBSTITUIÇÃO TRIBUTÁRIA PARA FRENTE E OS REFLEXOS NO DESENVOLVIMENTO
}

\author{
Maria de Fátima Ribeiro* \\ Lucas Pires Maciel**
}

RESUMO: O presente trabalho objetiva analisar a substituição tributária para frente, e a possibilidade de restituição quando ocorra diferença de valores entre a base presumida e a base real. Explicitou que há dois entendimentos dissonantes, uma vez que uma parcela defende a impossibilidade de restituição do imposto pago a maior e a outra parte assevera que é imprescindível a devolução do valor pago a maior. Foi grande a discussão acerca do tema, até que, por fim, o Supremo definiu o tema, determinando a devolução dos valores e modulando os efeitos pró Fisco, o que gera reflexos no direito ao desenvolvimento.

Palavras-chave: Direito ao Desenvolvimento; ICMS; Modulação dos Efeitos; Restituição; Substituição Tributária para Frente.

\section{ICMS REFUNDS PAYMENT FOR THE MOST IN CASES OF TAX REPLACEMENT FOR FRONT AND REFLECTIONS ON DEVELOPMENT}

\begin{abstract}
The present work analyze the tax substitution ahead, and the possibility of restitution when there is difference of values between the presumed base and the real base. He explained that there are two dissonant understandings, since a portion defends the impossibility of refund of the tax paid the greater and the other party asserts that it is essential to return the amount paid the greater. There was a great deal of discussion about the theme, until, finally, the Supreme defined the theme, determining the return of the values and modulating the effects for the Treasury, which generates reflections to development.
\end{abstract}

Keywords: Right to Development; ICMS; Modulation of Effects; Restitution; Tax Replacement Forward.

\footnotetext{
* Doutora em Direito Tributário pela PUC-SP, Pós Doutora em Direito Tributário pela Universidade de Lisboa, Professora do Programa de Mestrado e Doutorado em Direito da UNIMAR - Universidade de Marília, São Paulo, Brasil.E-mail mfat@sercomtel.com.br.

** Doutorando e Mestre em Direito pelo Programa de Mestrado e Doutorado em Direito da UNIMAR Universidade de Marília - São Paulo, Brasil. Especialista em Direito Tributário. Advogado e Professor do Centro Universitário Toledo de Presidente Prudente - São Paulo - Brasil. E-mail lucas_jppm@ hotmail.com.
} 


\section{INTRODUÇÃO}

O ICMS - Imposto sobre Circulação de Mercadorias e Serviços de Transporte Interestadual e Intermunicipal e de Comunicação - é um imposto de competência dos Estadosmembros e do Distrito Federal. Possui, nos termos da Constituição Federal (art. 155, II), várias regras-matrizes de incidência tributária.

Basicamente, podem-se considerar três regras-matrizes básicas: circulação de mercadorias; prestação de serviço de comunicação, e; prestação de serviço de transporte interestadual e intermunicipal.

É possível, a partir da Emenda Constitucional n ${ }^{\circ} 3$ de 1993, que incluiu o $\S 7^{\circ}$ no artigo 150 da Constituição Federal, que os entes competentes utilizem-se do instituto da substituição tributária. Neste caso, é atribuído à pessoa distinta do contribuinte o dever de pagar o imposto, com o objetivo de diminuir a inadimplência e facilitar a fiscalização do Fisco.

Assim, o Fisco atribui a uma única pessoa o pagamento do tributo de toda a operação. Há duas espécies de substituição tributária. A primeira é chamada de substituição pata trás em que ocorre a postergação do pagamento do tributo, sendo que caberá ao destinatário final do serviço ou do produto quitar o tributo devido.

Ademais, tem-se a substituição tributária denominada de para frente, em que aquele que dá origem a operação tem que recolher o tributo devido, realizando uma antecipação das futuras prestações de serviço ou de circulação de mercadoria. Nesta hipótese, há uma presunção da base de cálculo do valor final, uma vez que este ainda não se realizou de fato.

Na substituição para trás não há problema de eventual restituição de tributo pago, já que o valor do tributo é pago de uma única vez e ao final da operação, frente ao valor do produto ou serviço final e que efetivamente ocorreu.

Todavia, no caso da substituição para frente podem surgir alguns problemas de ordem prática, haja vista que como ocorre uma presunção do valor final da prestação de serviço ou da circulação de uma mercadoria, estas podem não ocorrer da forma como foram previstas, por uma série de questões.

Nestes casos, há que se vislumbrar o que preceitua o citado $\S 7^{\circ}$ do artigo 150 da Constituição Federal acerca do assunto, em que conclui que é "assegurada a imediata e preferencial restituição da quantia paga, caso não se realize o fato gerador presumido”. 
Portanto, a restituição é assegurada pela Constituição Federal sempre que o fato gerador presumido não se realize. Por muitos anos houve grande discussão judicial acerca da devolução ou não do tributo, quando o valor do fato gerador efetivo fosse distinto do fato gerador presumido e, assim, ficasse algum crédito em favor do contribuinte.

O tema foi escolhido, tendo em vista ser um assunto que na prática forense encontra campo demasiadamente fértil, além do que gera reflexos deveras importantes para o Direito ao Desenvolvimento e, por via reflexa, na questão econômica das empresas. Além do que, pode ocasionar problemas na órbita na neutralidade fiscal.

Para tanto, utilizar-se-á o método dedutivo, tendo como foco a doutrina e a legislação que envolvam o tema. O uso do método dedutivo decorre do fato de que se utilizará da regra geral dos temas propostos para a compreensão dos casos específicos para buscar alcançar as respostas necessárias do presente estudo.

\section{RESTITUIÇÃO DO ICMS PAgO A MAIOR NOS CASOS DE SUBSTITUIÇÃo TRIBUTÁRIA PARA FRENTE}

É cediço que, em regra, o contribuinte deve ser aquele sujeito responsável pelo pagamento do tributo. Contudo, essa regra possui exceções, em especial, os casos de responsabilidade previstas no Código Tributário Nacional e as hipóteses de substituição tributária.

Existe a substituição chamada de convencional, presente em casos como prestação de serviço, em que o tomador de serviço tem o dever de recolher o Imposto sobre Serviços e no caso de relação de emprego, ocasião em que o empregador deve descontar e recolher aos cofres da União os valores decorrentes da contribuição social e eventualmente do imposto sobre a renda.

Ademais, há a substituição tributária para trás, em que há um diferimento do pagamento do respectivo tributo e a substituição tributária para frente, em que ocorrerá um adiantamento do pagamento do tributo, com a fixação de um preço estimado de venda final. Essa última situação de substituição tributária é o objeto principal do presente artigo. 


\subsection{HISTÓRICO DA SUBSTITUIÇÃO TRIBUTÁRIA}

A substituição tributária foi introduzida no mecanismo legal pátrio através do Código Tributário Nacional (Lei $\left.n^{\circ} 5.172 / 66\right)$. O responsável por essa introdução foi o inciso II, do $\S$ $2^{\circ}$ do artigo 58.

A referida previsão ficou no sistema tributário até o Ato Complementar $n^{\circ} 34$, em meados de janeiro de 1967.

Ato contínuo foi editado o Decreto-lei $n^{\circ} 406 / 68$, que expressamente revogou o dispositivo acima. Com isso, não havia mais previsão legal acerca do tema. Ocorre que, passados quinze anos, foi publicada a Lei Complementar $n^{\circ} 44$, de 07/12/83, que editou a chamada "substituição tributária para frente". Note que foram incluídos parágrafos aos artigos $2^{\circ}, 3^{\circ}$ e $6^{\circ}$ do Decreto-lei no $406 / 68$.

Todo o breve resumo da história do instituto acima exposto foi obtido a partir da palestra proferida no Conselho de Justiça Federal ${ }^{1}$, em 21 de junho de 1996, pelo Senhor Doutor Ministro do Superior Tribunal de Justiça Antônio de Pádua Ribeiro. Seguindo ainda as lições do referido Congresso, o Ministro conclui:

Finalmente, a Constituição em vigor encampou o instituto (art. 155, § $2^{\circ}$, XII, b), tendo o Convênio n. 66/88 (com força de lei complementar, à vista do art. 34, § $8^{\circ}$, do ADCT) incluído no seu texto, praticamente, as normas da Lei Complementar n. 44, de 1983. Sobreveio, afinal, a Emenda Constitucional n. 3, de 17/03/93, que acrescentou o $\S 7^{\circ}$ ao art. 150 da Lei Maior, a cujo teor, antes, me referi.

Importante, após esses relatos acima, aduzir que foi instituído o $§ 7^{\circ}$ do artigo 150 da Constituição Federal:

Art. 150. Sem prejuízo de outras garantias asseguradas ao contribuinte, é vedado à União, aos Estados, ao Distrito Federal e aos Municípios:

$[\ldots]$

$\S 7^{\circ}$ - A lei poderá atribuir a sujeito passivo de obrigação tributária a condição de responsável pelo pagamento de imposto ou contribuição, cujo fato gerador deva ocorrer posteriormente, assegurada a imediata e preferencial restituição da quantia paga, caso não se realize o fato gerador presumido.

\footnotetext{
${ }^{1}$ Disponível em: <http://bdjur.stj.jus.br/dspace/handle/2011/173>. Acesso em: 30 ago. 2018.
} 
Finalmente, foi editada a Lei Complementar $n^{\circ} 87 / 96$, que prevê nos artigos de 5 a 10 sobre a substituição tributária na legislação infraconstitucional. Esse é, de forma breve, o histórico do instituto da substituição tributária no ordenamento brasileiro.

\title{
2.2 CONCEITO DE SUBSTITUIÇÃO TRIBUTÁRIA
}

O instituto da substituição tributária pela sua importância dentro da sistemática tributária nacional é discutido por vários doutrinadores. Importante expor alguns conceitos. Maria Rita Ferragut (FERRAGUT, 2005, p. 59-60), assim pronuncia-se:

\begin{abstract}
Substituição é proposição prescritiva (norma jurídica lato sensu) que prevê, em seu antecedente, uma relação direta ou indireta firmada entre o substituto e o substituído, ou direta entre o substituto e o fato jurídico tributário (tal como venda e compra de mercadorias, pagamento e recebimento de salário, pagamento e recebimento de honorários por serviços prestados etc.) e prescreve, em seu consequente, a obrigação de o substituto cumprir com a obrigação tributária gerada em virtude de fato juridicamente relevante praticado pelo substituído, ao mesmo tempo em que exonera este último de cumprir com a obrigação.
\end{abstract}

Já no entender de José Eduardo Soares de Melo (MELO, 2007, p. 143) substituição tributária é assim conceituada:

\footnotetext{
Trata-se a substituição de imputação de responsabilidade por obrigação tributária de terceiro que não praticou o fato gerador, mas que tem vinculação indireta com o real contribuinte. O substituto tem decorrer naturalmente do fato imponível, da materialidade descrita (hipoteticamente) na norma jurídica, não podendo ser configurado por mera ficção do legislador.
}

Pelos conceitos acima expostos, fica evidenciado que a substituição tributária atribui responsabilidade a um terceiro que não realizou a regra-matriz de incidência tributária, mas está intimamente ligado ao contribuinte de fato.

Ademais, rapidamente, pode-se dizer que este instituto foi criado para facilitar ao Fisco a fiscalização e, com isso, coibir a sonegação, uma vez, que com a substituição tributária, diminui consideravelmente o número de sujeitos à fiscalizar.

José Eduardo Soares de Melo corroborando com o que acima exposto assevera que o Fisco assim age "por razões de comodidade, praticidade ou pela circunstância de o real contribuinte não manter organização adequada de seus negócios” (MELO, 2007, p. 167). 


\subsection{ESPÉCIES DE SUBSTITUIÇÃO TRIBUTÁRIA}

Apresentada a introdução acima, insta demonstrar as espécies de substituição tributária existentes. Basicamente são duas, quais sejam, a substituição tributária para frente e a substituição tributária para trás. Roque Antonio Carrazza (CARRAZZA, 2003, p. 264) adota esta classificação. Há, também, a substituição tributária convencional. A primeira decorre de uma antecipação do fato imponível, num verdadeiro fato gerador presumido. Para Maria Rita Ferragut (FERRAGUT, 2005, p. 64):

Por fim, na sujeição passiva para frente (terceira hipótese) o substituto integra a relação jurídica, constituída anteriormente à própria ocorrência do evento que talvez seja no futuro praticado pelo substituído, e que por força da causalidade normativa deveria implicá-lo. É o denominado fato gerador presumido, norma jurídica que imputa a um fato indiciário da situação de provável ocorrência futura consequiências jurídicas próprias do fato jurídico típico tributário.

Ainda seguindo as ideias da citada autora "o nascimento da relação jurídica tributária não requer a ocorrência efetiva do fato típico, mas somente a expectativa, a suposição, a presunção relativa em indícios considerados aptos pela lei para provocar a ocorrência futura e por isso duvidosa e incerta - do evento" (FERRAGUT, 2005, p. 64-65).

Por fim na substituição tributária para trás ocorre um diferimento do pagamento do tributo, ou seja, há a postergação do momento da quitação do tributo. Para Roque Antonio Carrazza esta espécie de substituição tributária existe tendo em vista as dificuldades de fiscalização, notadamente dos pequenos produtores (onde mais se concentra esta forma jurídica), o diferimento permite que o pagamento do imposto devido sobre tais operações (acrescenta-se ainda os serviços a exemplo do que dispõe o artigo 88 do regulamento do ICMS paranaense) seja postergado e recolhido por outrem (CARRAZZA, 1999, p. 93). Maria Rita Ferragut (FERRAGUT, 2005, p. 64) assim assevera acerca dessa espécie de substituição tributária:

\footnotetext{
A primeira consiste na responsabilidade pelo pagamento de tributo relativo a operações ou prestações anteriores, ou seja, o diferimento. Aqui, a obrigação de pagar é adiada para momento posterior à operação tributada, como no caso da responsabilização do industrial pelo pagamento do imposto referente às operações de venda de insumos do produtor rural para a indústria. Não se confunde com a mera postergação do prazo de pagamento, já que o vencimento da obrigação condiciona-se a um outro fato futuro a ser praticado pelo substituto (indústria deverá promover a
} 
saída do insumo adquirido do produtor; ainda que o bem tenha sido alterado em função da industrialização).

Já a substituição convencional é a que ocorre quando a legislação atribui a um terceiro a responsabilidade no pagamento do tributo assim que ocorrido o fato gerador. Nas palavras de Maria Rita Ferragut, que ocorre no "exemplo do tomador do serviço pelo recolhimento do ISS retido do prestador; ou do recolhimento de IRRF pela fonte pagadora no envio de certos pagamentos ao exterior. Aqui também não há postergação, mas substituição (pré-jurídica) do sujeito devedor" (FERRAGUT, 2005, p. 64).

Analisada a substituição tributária, é importante tratar especificamente da substituição tributária para frente.

\subsection{SUBSTITUIÇÃO TRIBUTÁRIA PARA FRENTE}

Pela importância da substituição tributária para frente no tema do presente trabalho é de grande valia detalhar com mais detalhes essa espécie de substituição tributária. A substituição tributária para frente, com fundamento no artigo $150, \S 7^{\circ}$ da Constituição Federal, tem-se que a regra-matriz de incidência tributária ocorrerá no futuro e há a cobrança antecipada do tributo, ou seja, é feita uma presunção do fato que acontecerá futuramente. Para Sérgio Gonini Benício a substituição tributária para frente, ou, segundo ele, progressiva "se estrema das demais figuras subjetivas passivas em razão de o substituto ter que recolher valores atinentes a toda incidência tributária do ICMS, ao longo da cadeia circulatória, não obstante ainda não tenham sequer ocorrido os respectivos fatos geradores” (BENÍCIO, 2010, p. 136).

Para poder dar guarida para essa ficção da sujeição passiva tributária a Constituição Federal criou o chamado fato presumido, em que há um cálculo feito para se saber qual o valor que um determinado produto será vendido na última etapa de sua cadeia e antecipa-se o ICMS total, mesmo sem saber se efetivamente esse produto será vendido naquele valor estimado. Como previsto no artigo $150, \S 7^{\circ}$, da Constituição Federal, previu que no caso de não ocorrência do fato efetivo, garante-se a imediata e preferencial restituição da quantia paga.

Foi, por isso, editada a Lei Complementar 87/96, que confirmou tal possibilidade de restituição no caso de não ocorrência do fato gerador, no seu artigo 10. Veja-se, assim, que a legislação infraconstitucional, em reflexo ao comando constitucional, orienta a devolução do valor em até 90 (noventa) dias. Ocorre que a Constituição Federal foi completamente omissa 
quanto a questão da restituição do valor do fato efetivo, quando este tiver ocorrido de fato, mas em valor menor que o fato presumido, assunto que será melhor explorado no tópico a seguir.

Severas críticas, quanto a constitucionalidade, são feitas ao citado $\S 7^{\circ}$ do artigo 150 da Constituição Federal. Gilberto de Ulhôa Canto (CANTO, 1993, p. 136) aponta que:

[...] porquanto, na sua expressão constitucional, a hipótese de incidência do ICMS é a realização de operações de circulação de mercadorias realizadas por industriais, comerciantes ou produtores (uma vez que o texto fala em operações de circulação de mercadorias), e o concebe (citado inc. I do $\S 2^{\circ}$ do mesmo artigo) como comportando fatos geradores isolados e distintos em que o sujeito passivo seja quem promove a operação de que se trate, ou com ela tenha alguma vinculação.

A presunção de ocorrência de fato gerador (fato imponível) quantificado numa base de cálculo aleatória e meramente arrecadatória é inadmissível. valiosa a conclusão de Edvaldo Brito (BRITO, 1994, p. 439-440):

Portanto, o legislador competente para reformar a constituição jurídica não tem poder
constituinte que lhe autorize romper com o que a pragmática plasmou; ele não atua
em razão de qualquer ruptura da ordem jurídica e, assim não cria uma ordem jurídica
nova ... Enfim, ele não tem atribuições para subverter a disciplina do pensamento
humano, desempenhando tarefas como, por exemplo, as de definir que homem é
mulher; que noite é dia; ou que a escravidão é o sistema que promove a igualdade
entre os homens. Não há fato gerador presumido, sob pena de admitir a inadmissível
subversão, antes denunciada. O acréscimo do parágrafo $7^{\circ}$, na redação que lhe deu a
Emenda no $3 / 93$, ao art. 150 da Constituição jurídica, consiste em subtrair, sem justa
causa, a propriedade, cuja aquisição e exercício é direito inato do homem.

Com base nos entendimentos acima expostos vê-se a celeuma gerada pela Emenda Constitucional $\mathrm{n}^{\circ}$ 3. Fere de morte, indubitavelmente, vários princípios constitucionais tributários. Hugo de Brito Machado (MACHADO, 1993, p. 447), que considera injurídica a possibilidade de lei atribuir responsabilidade tributária por imposto relativo a evento futuro e incerto, litteris:

Seja como for, certo é que a norma em questão não autoriza o legislador a atribuir a responsabilidade tributária a um contribuinte, por imposto relativo a evento futuro e incerto. Em outras palavras, o que a norma em exame denomina fato gerador presumido é um fato cuja ocorrência se possa razoavelmente supor, porque algo que ordinariamente acontece numa correlação lógica com o fato que liga aquele a quem se atribui a responsabilidade tributária, ao sujeito passivo da obrigação tributária que surgirá daquele fato que se presume acontecer. Finalmente, não se pode descartar o argumento segundo o qual a norma do parágrafo $7^{\circ}$, do art. 150 , da Constituição é desprovida de validade, porque inconstitucional, não obstante resulte de Emenda à Constituição. É que as limitações constitucionais ao poder de tributar encartam-se ao patrimônio jurídico dos contribuintes como direitos fundamentais, e estes não podem sofrer restrições advindas de emendas, em virtude do disposto no art. $60, \S 4^{\circ}$, inciso 
IV, da Constituição Federal de 1988.

É importante consignar que a despeito de toda a facilitação trazida pelo instituto da substituição tributária, o instituto tem de ser visto com olhos atentos, uma vez que a sanha arrecadatória, muitas vezes ultrapassa os limites do razoável, como se vislumbra no caso da substituição tributária para frente. Neste sentido, sábias são as lições de Paulo de Barros Carvalho (CARVALHO, 2008, p. 161):

\begin{abstract}
O instituto da substituição desfruta de grande atualidade no Brasil, difundindo-se intensamente como vigoroso instrumento de controle racional e de fiscalização eficiente no processo de arrecadação dos tributos. Entretanto, ao mesmo tempo em que responde aos anseios de conforto e segurança das entidades tributantes, provoca sérias dúvidas no que concerne aos limites jurídicos de sua abrangência e à extensão de sua aplicabilidade. Afinal de contas, o impacto da repercussão fiscal mexe com valores fundamentais da pessoa humana - propriedade e liberdade -, de tal sorte que não se pode admitir transponha o legislador certos limites, representados por princípios lógico-jurídicos e também jurídico-positivos.
\end{abstract}

Assim, a aplicação da substituição tributária para frente fere de morte diversos princípios, quais sejam, o da legalidade, o da não-confiscatoriedade, da não-cumulatividade, o da segurança jurídica entre outros.

Inicialmente é bom tratar da aberração causada pela substituição tributária referente ao princípio da legalidade. É cediço que o citado princípio exige que para nascimento de um tributo necessária que este se verifique in concreto.

Paralelamente a isto, a substituição tributária fere o princípio da não-confiscatoriedade, uma vez que tributar um fato ainda não ocorrido poder-se-á estar tributando alguma operação que pode ser que não venha a ocorrer, o que nada mais é do que confiscar, uma vez que o ente competente tributa uma possível situação, ou seja, uma possibilidade. Neste sentido Roque Antonio Carrazza assevera que "não se pode ter certeza de que a mercadoria não perecerá ou de que será realmente objeto de operação mercantil. De qualquer modo, há incerteza sobre a ocorrência deste evento. Tributar esta situação de incerteza equivale a confiscar" (CARRAZZA, 2005, p. 114-115).

Ademais, é bom esclarecer que a substituição tributária analisada avilta o princípio da não-cumulatividade, que como já analisado em tópico acima, impossibilita que haja aplicação da tributação em cascata, aonde se aproveita o valor já pago na operação seguinte.

Os argumentos até aqui expostos dão conta da inconstitucionalidade do instituto da substituição tributária para frente. É assim que entende a maior parte da doutrina, inclusive 
alguns acima citados. Todavia, há uma outra parte da doutrina, composta de respeitáveis doutrinadores, dentre eles Hugo de Brito Machado e Aroldo Gomes de Mattos, que entendem pela constitucionalidade da Emenda Constitucional $n^{\circ} 3$, asseverando que o próprio $\S 7^{\circ}$ do artigo 150 da Constituição Federal prevê a hipótese de restituição do valor pago no caso de não acontecimento do fato imponível.

A despeito de todas essas críticas acerca da inconstitucionalidade da substituição tributária para frente, é bom esclarecer que o $§ 7^{\circ}$ está em vigor e deve ser aplicado, até que eventualmente os órgãos responsáveis o retirem da Constituição Federal. Até então, há que se debruçar o estudo nessa sistemática atual.

\subsection{RESTITUIÇÃO DO ICMS PAGO NA SUBSTITUIÇÃO TRIBUTÁRIA PARA FRENTE}

Conforme exposto no tópico acima, a substituição tributária para frente não apresenta maiores discussões quanto ao fato de não ocorrer o fato presumido, uma vez que garante a devolução dos valores pagos de maneira preferencial e imediata, conforme disposição constitucional. A discussão ganha contornos complexos quando a questão envolve a necessidade (ou não) de restituir ao substituto o valor pago a maior, considerando-se o fato presumido e o efetivo.

É certo que a Emenda Constitucional foi omissa com relação a possibilidade de restituição nesse caso. Por tal motivo, criou-se uma verdadeira celeuma, em que de um lado os contribuintes pleiteavam o valor pago a maior de volta e os Estados negavam-se a tanto, uma vez que desnudos de norma autorizadora.

Diante desse impasse criado, os Estados juntamente com o Distrito Federal editaram o Convênio ICMS $n^{\circ} 13$. Veja, portanto, que ficou decidido pela não restituição do ICMS na hipótese aventada. Obviamente, pela forma como agiram os Estados e o Distrito Federal, houve arguição de inconstitucionalidade da referida norma, por meio de Ação Direta de Inconstitucionalidade, que foi ajuizada perante o Supremo Tribunal Federal.

Essa Ação Direta de número 1.851-AL foi apreciada pelo Pretório Excelso que julgou a ação improcedente, o que confirmou a validade da citada cláusula segunda, permanecendo, desta forma, descabida a repetição dos valores recolhidos a maior decorrente da base presumida versus a base real. Vide a ementa da ADI $1.851^{2}$.

${ }^{2}$ EMENTA: TRIBUTÁRIO. ICMS. CONVÊNIO ICMS 13/97, CLÁUSULA 2.르. QUE REGULAMENTOU O
REGIME DE SUBSTITUIÇÃO TRIBUTÁRIA. PRETENDIDO ESCLARECIMENTO SOBRE SE A Rev. de Direito, Economia e Desenvolvimento Sustentável| e-ISSN: 2526-0057| Porto Alegre | v. 4 | n. 2 | p. 131 - 149 | Jul/Dez. 2018 
Sabidamente pela leitura da ementa ficou prevista a impossibilidade em restituir o imposto pago no caso de ocorrência do fato mesmo tendo sido a base de cálculo real menor do que a presumida. O citado Convênio ICMS não contou com a assinatura do Estado de São Paulo, que, por sua vez, preferiu promulgar lei. Assim editou a Lei $\mathrm{n}^{\circ}$ 9.176/95, a qual incluiu o artigo 66-B na Lei $n^{\circ} 6.374 / 89$, definindo que caso não se efetive o fato gerador presumido na sujeição passiva e caso se comprove que na operação final como mercadoria ou serviço ficou configurada obrigação tributária de valor inferior à presumida.

Note que a legislação estadual paulista ia contra o entendimento dos demais Estados da Federação, uma vez que permitia a restituição do imposto pago se a obrigação final tivesse valor inferior ao da base presumida.

Da mesma forma como ocorreu com a cláusula segunda, acima debatida, a referida lei paulista foi objeto de Ação Direta de Inconstitucionalidade. Assim, o Supremo Tribunal Federal entendeu ser definitivo o valor presumido para o cálculo do ICMS, no caso da análise da cláusula segunda. Todavia, não se pode considerar a decisão como definitiva, haja vista que o próprio Tribunal voltou a julgar a questão através da Ação Direta de Inconstitucionalidade $\mathrm{n}^{\circ}$ 2.777-SP, envolvendo a citada lei paulista, julgamento que se encontra em andamento.

Nesta ocasião houve um empate, haja vista que cinco Ministros, quais sejam, Cezar Peluso, Ricardo Lewandowski, Joaquim Barbosa, Marco Aurélio e Celso de Mello votaram pela procedência da ação, ou seja, pela inconstitucionalidade da lei paulista e de outro lado outros cinco Ministros - Nelson Jobim, Eros Grau, Gilmar Mendes, Ellen Gracie e Sepúlveda Pertence - , pelo indeferimento da ação de inconstitucionalidade. Falta apenas o voto do Ministro Carlos Ayres Brito.

Colocadas essas premissas, é importante passar a analisar a questão da possibilidade de restituição do ICMS pago a maior quando da aplicação da base presumida contra a base efetiva.

É certo que na doutrina e na jurisprudência há grandes altercações. De um lado os defensores da impossibilidade de restituir o imposto pago de forma excessiva aduzem que, por não haver autorização da Constituição Federal, não se pode concluir de maneira diversa. Aduzem que o texto constitucional apenas autoriza a imediata e preferencial devolução no caso

EFICÁCIA DO SISTEMA DEPENDE DA EDIÇÃO DE LEI ESTADUAL; QUAL SERIA O FATO GERADOR PRESUMIDO, CUJA NÃO-OCORRÊNCIA RENDERIA ENSEJO À APLICAÇÃO DA CLÁUSULA DE RESTITUIÇÃO DA QUANTIA INDEVIDAMENTE PAGA; E SE O REGIME DE SUBSTITUIÇÃO TRIBUTÁRIA É RESTRITO AO SETOR DE AUTOMÓVEIS. [...]. (ADI 1851 ED, Relator(a): Min. ILMAR GALVÃO, Tribunal Pleno, julgado em 19/03/2003, DJ 25-04-2003 PP-00032 EMENT VOL-02107-01 PP-00121)

Rev. de Direito, Economia e Desenvolvimento Sustentável| e-ISSN: 2526-0057| Porto Alegre | v. 4 | n. 2 | p. 131 - 149 | Jul/Dez. 2018 
de não ocorrência do fato efetivo. Uma outra parte da doutrina e da jurisprudência, vai ao contrário da corrente acima, advogando a favor da restituição.

Roque Antonio Carrazza (CARRAZZA, 2003, p. 279) elabora texto no sentido que a "substituição tributária para frente do ICMS é tanto mais absurdo na medida em que a Fazenda Estadual, de sua parte, tem o dever jurídico de arrecadar exatamente o que lhe é devido a título de imposto. Nem mais, nem menos".

Ademais, é de grande valia explicitar que para a aplicação da substituição tributária para frente no direito pátrio, passou-se a ter algumas limitações, que nos termos do que assevera Heleno Taveira Tôrres (TÔRRES, 2001, p. 87), são:

I. deve ser assegurada a imediata e preferencial restituição da quantia paga, caso não
se realize o fato gerador presumido;
II. por decorrência, o regime jurídico aplicável à tributação deve ser sempre o do
substituído e não do substituto, na medida em que a tributação definitiva deve se
verificar sempre sobre aquele; e
III. a lei definidora do regime típico aplicável deverá ser sempre a da data das
operações substituídas e não a da data da operação do substituto, cabendo-se a
necessária restituição do quanto eventualmente tenha sido pago a maior naquela
operação.

Por isso, seguindo as linhas acima, é implícito ao regime da substituição tributária para frente, a obrigatoriedade de devolução da diferença entre o valor pago pela base presumida e da real. Sem contar que, como já dito, a substituição tributária para frente é uma ferramenta criada para facilitar a arrecadação estatal e, por isso, deve obrigatoriamente ser interpretada restritivamente, para evitar que o sujeito passivo seja prejudicado.

Ademais, a partir do momento em que há uma presunção, ou seja, uma situação de precariedade, assim que ocorrida a situação na prática, a situação outrora preventiva torna-se definitiva, devendo a partir de então, esquecer-se daquela e valer esta, por uma questão de lógica.

Além do mais cabe neste momento as lições de Sérgio Gonini Benício (BENÍCIO, 2010, p. 137):

O uso de ficções ou presunções legais, para a regulamentação de aspectos da vida social, deve ser encarado como medida excepcional, que só deve ter lugar quando não houver outra solução legislativa igualmente hábil para atingir os mesmos efeitos e escopos. Sempre que possível for, assim, associar as normas jurídicas a situações reais e efetivas, em lugar de meros expedientes presumidos ou fictos, deverá o legislador optar pela primeira saída - mormente se a utilização de presunções ou ficções legais, for, potencial e factualmente, prejudicial às normas ou aos princípios mais elevados, postos em sede constitucional. 
É o que se vislumbra no caso da substituição tributária, uma vez que apenas com o fito de facilitar a arrecadação os fiscos criaram um mecanismo altamente prejudicial, haja vista que querem transformar em definitivo algo que é presumido.

A partir dessa análise, entendendo-se pelo pela devolução dos valores pagos a maior na base presumida, conclui-se que o pagamento feito, pelo menos a diferença, é considerado como indevido, e, por isso passível de devolução, nos termos das normas gerais do direito tributário.

Assim, seria como uma apropriação indevida do Estado desses valores pagos. Sacha Calmon Navarro Coelho aduz que a legislação deve assegurar três direitos básicos para aquele que é alvo de uma tributação antecipada, como no caso da substituição tributária para frente (COELHO, 1993, p. 321):

Primus - A imediata recuperação, indexada se for o caso, do imposto que compulsoriamente o substituto lhe cobrou, no caso de não vir a realizar o fato gerador suposto; Secundus - A compensação imediata do imposto retido a maior, se menor for o valor da operação, antes suposta; Tertius - O direito de o adquirente do substituído - se contribuinte for - aproveitar o crédito daquele imposto pago pelo substituto, para preservar o princípio da não cumulatividade.

A citação acima é bastante interessante, uma vez que advoga no sentido de ser característica da substituição a possibilidade de restituição do imposto retido a maior. Hugo de Brito Machado enaltece a necessidade de devolução do imposto pago indevidamente, nestes termos (MACHADO, 1997, p. 36):

\footnotetext{
Não podem, porém, as leis estaduais, excluir o direito do contribuinte substituído às diferenças, nas hipóteses de operação final com preço inferior ao valor que serviu de base a antecipação. Disposição nesse sentido seria inconstitucional, pela mesma razão que não se admite a pauta fiscal, vale dizer, por, desrespeito à norma da Constituição Federal que estabelece ser o imposto sobre operações relativas à circulação e mercadorias. Se o imposto incide sobre operações relativas à circulação de mercadoria, sua base de cálculo há de ser o valor de tais operações. No caso de venda, o preço correspondente.
}

Uma situação que deve ser pensada sobre esse assunto, também, está intimamente ligada com a questão da liberdade, prevista no artigo 170 da Constituição Federal. Veja bem: se se entender pela não possibilidade de devolução do ICMS pago a maior, por uma venda feita abaixo daquela presumida, em outras palavras está se acarretando uma quebra na liberdade de escolha de preço do lojista, gerando com isso um engessamento da economia e, consequentemente, o fim da concorrência. 
Por esse motivo, também, impacta diretamente no Direito ao Desenvolvimento, uma vez que ao impactar na liberdade de escolha do lojista, gera impactos econômicos e, assim, consequentemente interfere na economia do país, gerando um desequilíbrio na livre iniciativa e na neutralidade fiscal.

E mais, a partir disso, os que entendem contrariamente, esquecem que os atos de mercancia são decorrentes de direito disponível, ou seja, os donos das mercadorias podem dispor de seus produtos da maneira que quiserem. Por isso mesmo é bom citar Sérgio Gonini Benício ao ponderar que a margem de lucro presumida é calculada pelo próprio Fisco segundo seus critérios (BENÍCIO, 2010, p. 145).

A partir do momento em que há uma regra que aduz pela ausência de devolução dos valores antecipadamente recolhidos a título de ICMS, com base em um valor presumido, quebra-se toda essa cadeia, que, de uma forma ou de outra, fere o direito constitucional, dos mais importantes, o da liberdade. Além do mais convém apresentar as palavras de José Eduardo Soares de Melo (MELO, 2007, p. 189):

\footnotetext{
Se é relativa a presunção de inocorrência do fato gerador futuro, com mais forte razão também deve ser considerada relativa a presunção de que a futura operação não seja realizada exatamente pelo mesmo valor considerado à época da antecipação tributária. Realmente, é natural a existência de oscilações de mercado concernentes a questões peculiares envolvendo vendedor e consumidor (descontos, antecipações, etc.)
}

Assim, sem dúvida, não permitir ao sujeito passivo que repita o que pagou antecipadamente, quando o fato efetivo teve uma base menor, seria desprestigiar o tão prestigiado princípio da não-cumulatividade, o que não se pode aceitar que uma viga mestra do sistema tributário seja tão abalada. Essa conclusão é extraída das lições de Roque Antonio Carrazza aduzindo que se não for assegurado ao contribuinte o creditamento do valor excedente ao das operações ou prestações realizadas, criar-se-á, visível inconstitucionalidade, além de uma restrição ao princípio da não-cumulatividade do ICMS: a estimativa superior à realidade (CARRAZZA, 2003, p. 287).

Este valor a maior não pode ser ignorado, sob pena de ignorar-se o princípio da nãocumulatividade. O Egrégio Superior Tribunal de Justiça, ao apreciar casos envolvendo a discussão em tela, posicionou-se favorável a devolução dos valores pagos em excesso: REsp 239510/ES, Rel. Ministro JOSÉ DELGADO, PRIMEIRA TURMA, julgado em 24/02/2000, DJ 20/03/2000, p. 51. Importante para compilar o que foi dito até aqui com as palavras de Leandro Paulsen (PAULSEN, 2008, p. 281): 


\begin{abstract}
A garantia prevista neste $\S 7^{\circ}$, de imediata e preferencial restituição da quantia paga, caso não se realize o fato gerador presumido, deve ser entendida em todo o seu significado: caso não se realize o fato gerador presumido, tal qual presumido. Ocorrendo o fato, mas em dimensão distinta da presumida, com operação em valores menores, temos realidade que exige um acerto de contas. Entendemos que não se pode admitir os diplomas legislativos que vêm surgindo e que negam a restituição quando o fato gerador venha a ocorrer, mas o valor da operação seja inferior ao presumido. Prever a antecipação dos pagamentos é admissível, mas admitir que o montante presumido da operação prevaleça sobre o montante real (legítima base de cálculo) é tolerar que se extrapole as normas de competência. De fato, a norma que concede competência aos Estados para tributarem a circulação de mercadorias só admite que sejam onerados na proporção da riqueza efetivamente revelada pelas respectivas operações; da mesma forma, a norma que concede competência à União para tributar a receita não admite senão o cálculo do tributo conforme a receita efetivamente ocorrida.
\end{abstract}

Obtempera-se pela leitura atenta do trecho acima que, além das várias atrocidades cometidas pela negativa em restituir o valor pago a maior, ainda há que se atentar para a quebra do Pacto Federativo, como bem menciona o autor, haja vista que privilegia um ente em detrimento dos demais.

Portanto, ficou evidenciado por todo o exposto que a despeito da ausência de previsão expressa da Constituição Federal quanto à possibilidade de devolução do valor do ICMS pago por meio da substituição tributária para frente, no caso de a base presumida ser maior que a real, há que se realizar uma análise sistemática da estrutura constitucional-tributária, e com isso assegurar que esse valor deve ser restituído, para evitar, assim, que se firam as normas constitucionais tributárias vigentes.

Assim, com base nessas linhas apresentadas, em recente julgado o Supremo modificou o entendimento que outrora possuía e garantiu a possibilidade de devolução do ICMS pago a maior na substituição tributária para frente, no $\operatorname{RE~} n^{\circ} 593.849^{3}$, de relatoria do Ministro Edson Fachin. Nesse caso houve mudança significativa de entendimento do Supremo e, com base nisso, o Supremo determinou a modulação dos efeitos em favor do Fisco, com bojo na segurança jurídica. Isso, pois, tempos antes, o Supremo decidia pela impossibilidade de repetição desses valores.

Foi fixada também a tese do julgamento para fim de repercussão geral: "É devida a restituição da diferença do Imposto sobre Circulação de Mercadorias e Serviços (ICMS) pago

\footnotetext{
${ }^{3}$ Disponível em: <http://www.stf.jus.br/portal/cms/verNoticiaDetalhe.asp?idConteudo=327683>. Acesso em: 18 jan. 2018.
}

Rev. de Direito, Economia e Desenvolvimento Sustentável| e-ISSN: 2526-0057| Porto Alegre | v. 4 | n. 2 | p. 131 - 149 | 
a mais no regime de substituição tributária para a frente se a base de cálculo efetiva da operação for inferior à presumida"»4.

Nesse caso, agiu com correção o Supremo ao modular os efeitos, pois permitir a devolução dos tributos em favor dos contribuintes seria espancar o princípio da segurança jurídica, em total desrespeito ao sistema constitucional tributário e prejudicando o Fisco.

\section{CONSIDERAÇÕES FINAIS}

Na substituição tributária "para trás" há um diferimento do pagamento do tributo, ou seja, há a postergação do momento da quitação do tributo. Já a substituição convencional é a que ocorre quando a legislação atribui a um terceiro a responsabilidade pelo pagamento do tributo assim que ocorrido o fato gerador. A substituição tributária "para frente" decorre de uma antecipação do fato imponível, em que a base de cálculo é presumida da venda que ocorrerá no futuro, com fundamento no artigo 150, $\S 7^{\circ}$ da Constituição Federal, instituída pela Emenda Constitucional $n^{\circ} 3$.

Há várias discussões quanto a inconstitucionalidade desse texto constitucional, por violar vários princípios constitucionais. A despeito desse entendimento, o fato é que o $\S 7^{\circ}$ do artigo 150 da Constituição Federal está em vigor e, por isso, enquanto não sair do sistema constitucional é tido como aplicável. O citado texto constitucional prevê que no caso de não ocorrência do fato efetivo, garante-se a imediata e preferencial restituição da quantia paga.

Nada se pronuncia quanto à hipótese de a base presumida ser diferente da base real, fato em que esta é menor do que aquela, se é devida a devolução do valor do ICMS pago em excesso.

Os Estados, exceto o Estado de São Paulo, juntamente com o Distrito Federal editaram o Convênio ICMS no 13 , que vedava a devolução do valor pago a maior. O citado veículo normativo foi objeto de análise constitucional por parte do Supremo Tribunal Federal. Nesta ocasião, o Tribunal declarou a constitucionalidade.

O referido tema é debatido na doutrina, e há quem entenda pela irrepetibilidade do ICMS pago na situação apontada, uma vez que o próprio texto constitucional apenas autoriza

\footnotetext{
${ }^{4}$ Disponível em:

<http://www.stf.jus.br/portal/jurisprudenciaRepercussao/verAndamentoProcesso.asp?incidente=2642284\&nume roProcesso=593849\&classeProcesso=RE\&numeroTema=201>. Acesso em: 18 jan. 2018.
} 
da devolução no caso de não ocorrência do fato gerador. Há, todavia, uma outra parte da doutrina que entende ser devida a devolução.

Para fundamentar pode-se asseverar que se não entender dessa forma haverá enriquecimento sem causa do Fisco, e que essa restituição é implícita na substituição tributária para frente.

A base presumida não pode ser vertida em definitiva, a não ser que a presumida e a definitiva sejam idênticas, uma vez que como o próprio nome diz é apenas presumida, devendose aguardar a efetiva para ter a operação como perfectibilizada.

Não aceitar a restituição da diferença causa uma quebra na liberdade empresarial das empresas, uma vez que ocorre um engessamento nos preços, acabando com a concorrência e liberdade de negociação.

Além disso, há um ferimento ao Pacto Federativo, uma vez que os Estados e o Distrito Federal, ao não se permitir a devolução, perceberá um valor diverso da previsão legal, algo que não é permitido aos outros Entes.

Assim, mesmo não havendo previsão expressa na Constituição Federal, por uma visão sistemática do texto constitucional, deve-se entender pela possibilidade de restituição do ICMS, no caso da substituição tributária para frente, em ocorrendo de o preço presumido ser maior que o preço da venda efetiva.

O Supremo Tribunal Federal, após muitos anos de discussão definiu que é devida a restituição da diferença do Imposto sobre Circulação de Mercadorias e Serviços (ICMS) pago a mais no regime de substituição tributária para a frente se a base de cálculo efetiva da operação for inferior à presumida.

Ademais, agiu com correção o Supremo ao modular os efeitos, pois permitir a devolução dos tributos em favor dos contribuintes seria espancar o princípio da segurança jurídica, em total desrespeito ao sistema constitucional tributário e prejudicando o Fisco, tendo em vista a mudança brusca de entendimento jurisprudencial.

Com isso, houve uma mitigação dos efeitos graves que a impossibilidade de restituição dos valores pagos a maior a título de ICMS, decorrente da substituição tributária para frente, ocasionavam antes dessa decisão acertada do STF. Assim, permitindo a restituição, ainda que vedada para os casos anteriores, amenizou as consequências e possibilitou uma melhoria no Direito ao Desenvolvimento e na efetivação do princípio da neutralidade fiscal. 


\section{REFERÊNCIAS}

BENÍCIO, Sérgio Gonini. Apontamentos teóricos e práticos sobre a substituição tributária.

São Paulo: Saraiva, 2010.

BRASIL. Supremo Tribunal Federal. Constitucional e Tributário. ICMS. Substituição Tributária nº 1.851/AL. Requerente: Confederação Nacional do Comércio - CNC. Relator Ilmar Galvão. Brasília, 19 de março de 2003. Disponível em: http://www.stf.jus.br/portal/jurisprudencia/listarJurisprudencia.asp?s1=\%281851\%2ENUME \%2E+OU+1851\%2EACMS\%2E\%29\&base=baseAcordaos. Acesso em: 18 ago. 2018.

BRASIL. Supremo Tribunal Federal. Constitucional e Tributário. ICMS. Substituição Tributária nº 2.777/SP. Requerente: Governador do Estado de São Paulo. Relator Cezar Peluso. Brasília, 19 de outubro de 2016. Disponível em: $<$ http://stf.jus.br/portal/diarioJustica/listarDiarioJustica.asp?tipoPesquisaDJ=AP\&classe=ADI \&numero=2777> . Acesso em: 31 ago. 2018.

BRASIL. Supremo Tribunal Federal. Constitucional e Tributário. ICMS. Substituição Tributária n 593.849/MG. Requerente: Parati Petróleo Ltda. Relator Edson Fachin. Brasília, 31 de março de 2017.2 Disponível em: <http://portal.stf.jus.br/processos/detalhe.asp?incidente=2642284>. Acesso em: 31 ago. 2018. BRASIL. Ministério da Fazenda. Convênio ICMS 13/97. Harmoniza procedimento referente a aplicação do $\S 7^{\circ}$, artigo 150, da Constituição Federal e do artigo 10 da Lei Complementar 87/96, de 13.09.96. Disponível em: <https://www.confaz.fazenda.gov.br/legislacao/convenios/1997/CV013_97>. Acesso em: 31 ago. 2018.

BRASIL. Superior Tribunal de Justiça. Tributário e Processual Civil. Substituição Tributária. $n^{\circ}$ 239.510/ES. Recorrente: Estado do Espírito Santo. Recorrido: Vitoriawagen S/A Comércio e Serviço de Automóveis. Relator: José Delgado. Brasília. Disponível em: $<$ http://www.stj.jus.br/SCON/jurisprudencia/doc.jsp?livre=239510\&\&b=ACOR\&p=true \&t= $\& \mathrm{l}=10 \& \mathrm{i}=7>$. Acesso em: 20 ago. 2018.

BRITO, Edvaldo Pereira de. Curso de Direito Tributário, vol. 2, $3^{\text {a }}$ ed., CEJUP, 1994.

CANTO, Gilberto de Ulhôa. Princípios Constitucionais Tributários. In Caderno de Pesquisas Tributárias, n 18, Resenha Tributária, São Paulo: Revista dos Trinunais, 1993. 
CARVALHO, Paulo de Barros. Direito tributário, linguagem e método. 2. ed., São Paulo: Noeses, 2008.

CARRAZZA, Roque Antonio. Curso de direito constitucional tributário. 19. ed., São Paulo: Malheiros, 2003.

Curso de direito constitucional tributário. 21. ed., São Paulo: Malheiros, 2005.

ICMS. 10. ed., São Paulo: Malheiros, 2005.

ICMS. 5. ed., São Paulo: Malheiros, 1999.

COÊLHO, Sacha Calmon Navarro. Comentários à constituição de 1988. 7. ed., Rio de Janeiro: Forense, 1998.

FERRAGUT, Maria Rita. Responsabilidade tributária e o código civil de 2002. São Paulo: Noeses, 2005.

MACHADO, Hugo de Brito. Curso de direito tributário. 30. ed., São Paulo: Malheiros, 2009. In Repertório IOB de Jurisprudência. São Paulo: Informações Objetivas,1993 - I, ementa $1 / 6853$.

MELO, José Eduardo Soares de. Curso de direito tributário. 7. ed., São Paulo: Dialética, 2007.

PAULSEN, Leandro. Curso de direito tributário. 2. ed., Porto Alegre: Livraria do Advogado, 2008 .

Direito tributário: constituição e código tributário à luz da doutrina e da jurisprudência. 10. ed., Livraria do Advogado: Porto Alegre, 2008.

RIBEIRO, Antonio de Pádua Ribeiro. Conselho de Justiça Federal, em 21 de junho de 1996. Senhor Doutor Ministro do Superior Tribunal de Justiça Antônio de Pádua Ribeiro, disponível em: 〈http://bdjur.stj.jus.br/dspace/handle/2011/173>. Acesso em: 30 ago. 2018.

SABBAG, Eduardo. Manual de direito tributário. São Paulo: Saraiva, 2009. Direito tributário. 9. ed., São Paulo: Premier Máxima, 2008.

TÔRRES, Heleno Taveira. Substituição tributária - regime constitucional, classificação e relações jurídicas (materiais e processuais). In Revista Dialética de Direito Tributário $\mathrm{n}^{\mathrm{o}} 70$. São Paulo: Dialética, junho/julho de 2001. 